\title{
تنمية مهارة الكلام في تعليم اللغة العربية بالمعهد العالي للأسعدية سنكامغ
}

$$
\text { قهارالدين }
$$

طالب برنامج الدكتوراه فن الدراسات العليا بجامعة علاء الدين الإسلامية الحكومية ومحاضر اللغة العربية في جامعة فرى فارى الإسلامية الحكومية

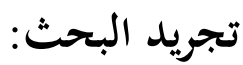

قام بعض المعاهد التربوية الإسلامية (الباسنترينات) بالتجديد في فن تعليم اللغة العربية لمواكبة متطليات العصر. فهذه المعاهد تزيد هدف تعليم اللغة العربية, ليس لمهارة قراءة الكتب فحسب, بل لمهارة لغوية أخرى أيضا. وإستخدمت الطريقة المباشرة في تعليمها بجانب طريقة القواعد والترجمة. ويجرى هذا تعليم اللغة العربية على إستعمال طريقة القواعد والترجمة, والطريقة المباشرة. والمعهد العاليى -من المؤسسات التربوبة في معهدالأسعدية- من المعاهد الذى يولّف تلك الطرق في تعليم اللغة العربية. يتعلم الطلبة فيه العلوم الشريعة ويحاول أن يجعلهم متعمقين فيها كي يستطيعوا أن يتفقهوا فن الدين. وطبّق الطريقة القديمة التى تحف إلى قدرة قراءة الكتب الصفراء وطبّق الطريقة الحديثة أيضا التى تَدف إلى قدرة مهارة الكلام ويحاول عدة محاولات في تنمية مهارى الكلام.

$$
\text { (الكلمات الأساسية: الكلام, العربية) }
$$




\begin{abstract}
ABSTRAK
Beberapa lembaga pendidikan Islam (Pesantren) telah memperbarui dalam pengajaran bahasa Arab untuk mengikuti modernisme zaman. Lembaga-lembaga ini meningkatkan tujuan mengajar bahasa Arab, tidak hanya untuk keterampilan membaca buku, tetapi juga untuk keterampilan bahasa lainnya. Metode pengajaran langsung digunakan bersamaan dengan metode tata bahasa dan terjemahan. Ini dilakukan dengan mengajarkan bahasa Arab menggunakan metode tata bahasa dan terjemahan, dan metode langsung.

Ma'had Aly - salah satu lembaga pendidikan di pesantren As'adiyah - sebuah lembaga yang mengintegrasikan metode-metode ini dalam pengajaran bahasa Arab. Siswa belajar sains dalam ilmu agama dan berusaha untuk mendalaminya sehingga mereka dapat memahami agama secara mendalam. Dia menerapkan metode lama membaca buku-buku kuning dan menerapkan metode modern juga ditujukan pada kemampuan keterampilan berbicara dan mencoba beberapa upaya dalam pengembangan keterampilan berbicara.
\end{abstract}

Kata Kunci: Berbicara, Bahasa Arab

\title{
أ. أ. مقدمة
}

إن تعليم اللغة العربية في جميع المراحل الدراسية الآن يهدف إلى تدريس المهارات

اللغوية الأربع و وتنميتها وهي الاستماع والكلام والقراءة والكتابة. ويحث المنهج أيضا أن يكون تدريس اللغة العربية لمستوى المبتدئين أن يشدد إلى حصول على مهارة الاستماع والكالام. ومهارة الكلام من المهارات اللغوية الأربع التى تمدف إلى تنمية القدرة الكلامية عند الدارسين حينما يتكلمون مع الأخرين.

ومهارة الكالام تعتبر مهارة ثانية من المهارة اللغوية الأربع بعد الإستماع. وتكون

مهارة مهمة في عملية تعليم اللغة العربية لغير الناطقين بها, لإن من الأهداف الأساسية اليوم في تعليم اللغة لغير الناطقين بها قدرة المتعلم على التكلم. لذلك النطق هو من أهم الجوانب 
فيها. والنطق هو المظهر الخارجي لعملية الكلام, فالمستمع لايرى من عملية التعلم إلا هذا المظهر الخارجى لها. ومن هذا, يجب أن يكون النطق سليما وواضحا خاليا من الأخطاء. والنطق أكثر عناصر الكلام صعوبة في تغييره أو تصحيحه بعد تعلمه بشكل خحاطئ. ولذلك التدريب على السيطرة والقدرة على الإخراج الأصوات بالشكل الذى يمكن المتعلم من الكلام مع أبناء اللغة بصرف النظر عن الدقة الكاملة في إخارج أصواهم ونيراهم

$$
\text { وتنغيمهم من أهمية أمور . } 1
$$

فن الواقع, تعليم مهارة الكالام حتى الأن مازال تحت سيطرة المعلم ولا يتيح الفرصة لدى الطلاب ليشتركوا بجها ونشاط في الأنشطة التعليمية والتدريبات حتى أن الدارسين لم يستطيعوا أن يتكلموا باللغة العربية ويشعرون بالملل فن تعلم اللغة العربية. وحديث المعلم أمام التلاميذ باللهجة العامية وعدم إستغلاله لفرصة التدريب على التعبير في بقية فروع اللغة العربية وعدم إهتمامه بتوليد الدافع وإقتناص الفرصة المطابقة, ها هي المشكلة.

ومعهد الأسعدية أحد المعاهد الموجود في إندونيسيا. يقع فن سنكانغ إحدى المناطق فى سلاويسى الجنوبية. يعتبر من المعاهد القديمة في هذه المنطقة. وأسّسه عالم العلامة الحاج محمد الأسعد البوغيسى المتوفى في التاريخ التاسع من دوسمبير سنة 1952 م. والأسعدية هو إسم لهذا المعهد يستعمل بعد وفاته, ويسمى قبله بالمدرسة العربية الإسلامية.

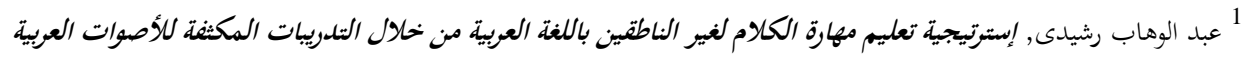

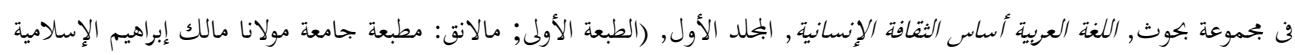
الحكومية, 2015 ), ص. صـ 627.

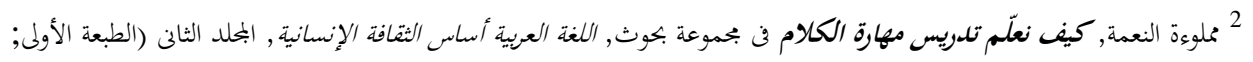

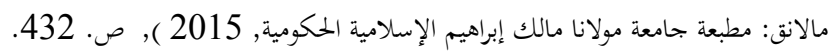


في هذا المعهد مستوى دراسي يسمى بالمعهد العالي. يتعلم الطلبة فيه العلوم الشريعة كلها ولا يتعلّمون العلوم العمومية وهم يدرسون التفسير وأصوله, وعلوم اللغة العربية. لذلك, أن المعهد العالي يركّز تعليمه في دراسة تلك العلوم ويحاول أن يجعلهم متعمقين فيها كي يستطيعوا أن يتفقهوا في الدين. بجانب تطبيق أهم أخذوا يطبقون التعليم بواسطة إستعمال الطريقة المباشرة والطريقة الأخرى التى تمدف إلى تنمية مهارة الكلام. ويجرى هذا

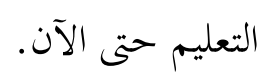

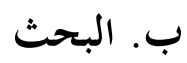

\section{1}

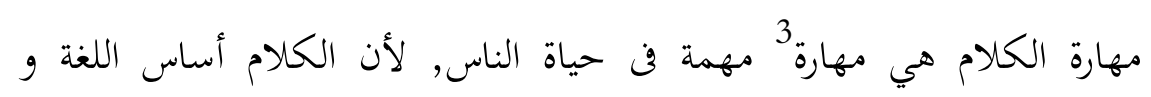

حقيقتها واللغة أساس النشاط الشفوي أو الكلام. قد تكلم الانسان قبل أن يكتبها. فكل متعلم لأي لغة، يهدف في البداية إلى إستعمالها و التكلم ليعبر عن أغراضه ويتصل مع

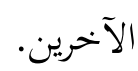

إن الكلام ب في اللغة الثانية من المهارات الأساسية التي تمثل غاية من غايات

الدراسة اللغوية, وإن كان هو نفسه وسيلة للاتصال مع الآخرين. ولقد إشتدت الحاجة لهذه المهارة في بداية النصف الثاني من القرن العشرين بعد إنتهاء الحرب العالمية الثانية، وتزايد

3 عرفت كلمة "مهارة" بأها الحذق والإجادة بكل عمل. وهي مصدر من مهر - بعهر - مهرا ومهورا ومهارا ومهارة الشئ وفيه وبه:

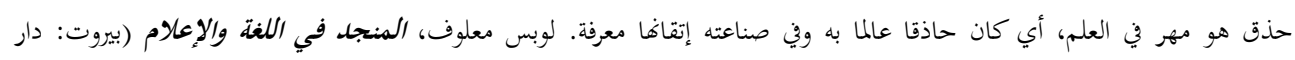

$$
\text { المشرف، 1986م) ص. 26. } 26 \text { ملكام في أصل اللغة هو "الإبانة والإفصاح عما يجول في خاطر الإنسان من أفكار ومشاعره بحيث يفهمه الآخرون }
$$


وسائل الاتصال، والتحرك الواسع من بلد إلى بلد، حتى لقد أدى تزايد الحاجة للاتصال الشفهي بين الناس إلى إعادة النظر في طرق تعليم اللغة الثانية. وإن مهارة الكلام في تعليم اللغة العربية هي القدرة على التحدث باللغة العربية صحيحا وفصيحا. وأهدافها الأساسية في تعليم اللغة العربية هي يستطيع الطلبة أن يتكلموا اللغة العربية تكلما صحيحا. إذن ,أن الكلام يطلب من المتعلم القدرة على إستعمال أصوات اللغة بصورة صحيحة. وهذا يحقق في مرحلة السماع والتمكن من الصيغ الصرفية ونظام تركيب الكلمات. وفي الأخير القدرة على حسن صياغة اللغة في إطارها الاجتماعي. من هنا تظهر أهمية الكام في تعلم اللغات، وإذا ما أهملت هذه المهارة أو أخرت لفترة زمنية معينة، كان ذلك عقبة كبيرة في تعليم اللغة كلها، لأن المتعلم يقبل على تعلم اللغة و هو يهدف أساسيا إلى إستعمالها شفويا، وعندما تمر الأيام دون أن يتمكن من ذلك، يحدث له نوع من الإحباط، ,ويشعر بأن التحدث بهذه اللغة أمر صعب المنال. 2.محاولات تنمية مهارة الكلام فى تعليم اللغة العربية بالمعهد العالي

لأسعدية سنكانغ

في الواقع, يستخدم المعهد العالي للأسعدية سنكانغ عدة طرق فن إجراء التعليم. ويتعلم الطلبة المواد النحوية والصرفية في الفصل أو خارج الفصل, حيث كان المعلمون 5 أنظر إلى رشدي أممد طعيمة، تعليم اللغة العربية لغير الناطقين بها، مناهجه وأساليبه (الرباط : منشورات المنظمة الإسلامية للتربية

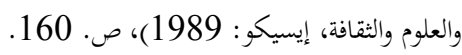

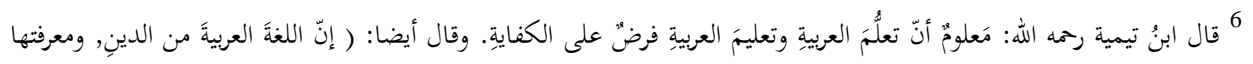

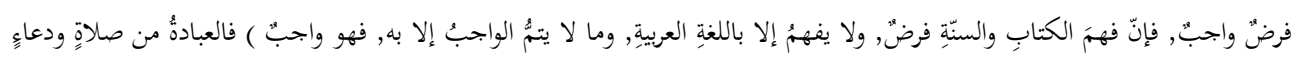

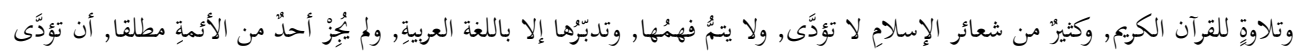

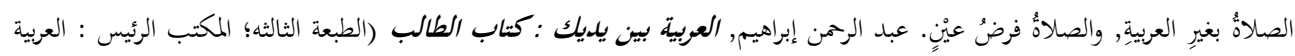

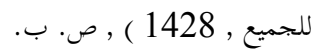


يشرحوفا من جهة القواعد ويعينون الكلمات فن موقع الإعراب وحمكه مرفوعا, منصوبا, بجوروا, وبجزوما. بالإضافة إلى هذا, أن المعلمين حينما يلقون الدروس فن الحلقة التراثية التى يقوم بها المعهد العالي بعد الصبح والمغرب يشرحون الكتب الدينية العربية ويحللوفها من جهة القواعد النحوية والصرفية. ومع مرور الزمان, أن المعلمين والطلبة في هذا المعهد يشعرون بالنقصان في تعليم اللغة العربية. وتكون عملية التعليم تركز فى مهارة القراءة والترجمة فقط. ولذلك, أفم أخذوا يطبقون التعليم بواسطة إستعمال الطريقة المباشرة والطريقة الأخرى التى تهدف إلى تنمية مهارة الكلام. ويجرى هذا التعليم حتى الآن. ومن تلك المحاولات التي يقوم بها المعهد العالي في تنمية مهارة الكلام مايلي: أ) إِ إستعمال اللغة العربية كلغة التعليم ب) القيام بالأنشطة الإضافية في المساء, والأنشطة المتخصصة ج. - (القيام باليوم العربي د) الواجبة بالتكلم العربية حينما يستأذن الطلية إذا أرادوا أن يخرجوا من المعهد. هـ) تحضير المحاضر العربي من البلاد العربية. و ) التعويد للطلبة في إستعمال اللغة العربية في الحال المعين. ز) الندوة العربية الأسبوعية أو الشهرية. ح) المحادثة العربية فن مسكن الطلاب والطالبات. ط) الحلقة العربية كل سنة ج. الخلاصة 
1. إن مهارة الكلام فن تعليم اللغة العربية هي القدرة على التحدث باللغة العربية صحيحا وفصيحا, حتى يستطيع الطلبة أن يتكلموا اللغة العربية تكلما صحيحا وفصيحا. والكالام ليس فرعا لغويا معزولا عن باق فروع اللغة العربية، بل هو الغاية من دراسة كل فروع اللغة العربية.

2.إن المعهد العالي للأسعدية يقوم بعدة محاولات في تنمية مهارة الكلام, منها التعليم الإضافي لتطبيق اللغة العربية كلغة يومية وإستعمال اللغة العربية في أنشطتهم اليومية وأثناء التعليم والتعلم. ويقوم ببرامج لغوية كالإجتماع العربي الأسبوعي السنوي والمحاضرة

$$
\text { د. العربية وغيرها من المحاولات الأخرى. }
$$

إبراهيم, عبد الرحم, العربية بين يديك :كتاب الطالب (الطبعة الثالثه؛ المكتب الرئيس : العربية للجميع , 1428.

رشيدى, عبد الوهاب, إستتيجية تعليم مهارة الكالام لغير الناطقين باللغة العربية من خلال التلديبات المكثثة للأصوات العربية فن مجموعة بحوث, اللغة العربية أساس الثقافة الإنسانية, البحلد الأول, الطبعة الأولى; مالانق: مطبعة جامعة مولانا

$$
\text { مالك إبراهيم الإسلامية الحكومية, } 2015
$$

طعيمة, رشدي أحمد ، تعليم اللغة العربية لغير الناطقين بها، مناهجه وأساليبه, الرباط : منشورات المنظمة الإسلامية للتربية والعلوم والثقافة، إيسيكو : 1989. معلوف, لوبس ، المنجد في اللغة والإعلام,بيروت: دار المشرف، 1986م. 
216 | Kaharuddin

النعمة, مملوةة, كيف نعلّم تلدريس مهارة الكلام في بحموعة بحوث, اللغة العربية أساس

الثقافة الإنسانية, المجلد الثاني, الطبعة الأولى; مالانق: مطبعة جامعة مولانا مالك

$$
\text { إبراهيم الإسلامية الحكومية, } 2015
$$

